\title{
New perspectives of biogas use
}

\author{
Lyubov Zazykina*, and Valentin Gusev
}

Federal State Budget Scientific Institution Federal Scientific Center "All-Russian Research and Technological Poultry Institute" of Russian Academy of Sciences, Pticegradskaya str., 10, 141311

Sergiev Posad, Russia

\begin{abstract}
The article is a comparison of existing facilities for processing poultry waste into bio energy. Currently, poultry farms have difficulties selling their secondary production, because only some of them have land plots. Thus, according to the statistics, the use of organic fertilizers in Russia decreased by seven times over the past 20 years, and now only 0.9 1.3 tons of waste are used per 1 ha of sowing. Meanwhile, poultry population has not decreased, so this waste is not disposed properly. The most crucial task for modern managers is to neutralize and rational use waste, making recycling at the poultry farms. This problem can be solved only by taking into account social and economical consequences, when making economic decisions. Consequently, such a method of decisionmaking could improve the farms' competitiveness will be enhanced by using secondary production (particularly poultry waste) as biogas.
\end{abstract}

\section{Introduction}

The latter tend to decrease despite the achievement of several indicators declared in the Food Security Doctrine and positive dynamics of egg and poultry meat production growth. However, many enterprises experience the shortage of working assets for realizing their potential despite the presence of steady demand. As a rule, enterprises' policy is focused on satisfying customer requests for the range and quality of products.

The main factors contributing to this situation are the disparity of prices for resources and products, solvency, inflation, fluctuations in ruble exchange rate, insufficient government support under fierce competition. A manufacturer who produces goods with lower feed and energy costs always wins in the agricultural market. In this case, competitiveness can be enhanced by using secondary production, particularly poultry waste, as biogas.

\section{Materials and Methods}

Currently, there are such types of waste in the industry as feathers, poultry mortality, eggs and others. Therewith, poultry waste being improperly disposed pollutes the environment and increases business expenditure.

Its main uses can be:

\footnotetext{
*Corresponding author: 1.zazykina@ya.ru
} 
- Composting.

- Vermicomposting (option: processing poultry waste by insects and worms).

- Microbiological conversion of manure and poultry waste.

- Biogas production technology (option: methane digestion).

- Pyrolysis (option: free-oxygen thermal waste decomposition).

- Combustion technology for thermal energy production.

- Combustion technology for alternative electrical energy production.

Production of biogas is one of the promising areas.

Monographic, statistical, economic and abstract-logical methods as well as comparative analysis were used while studying the issue of poultry waste processing

\section{Results and Discussion}

Let us analyze the biofuel markets to identify trends and demand for various types of resources.

There are two world markets for biofuels, specifically, the liquid market and the solid biofuel market. Both are rapidly and dynamically developing. However, they have fundamentally different geography of production and consumption, pricing mechanisms as well as the structure of supply and demand. Such differences are primarily associated with production technologies, biofuels application range. According to analysts, oil consumption will increase until 2020 and reach 88 million barrels per day, then it will steadily fall and drop to almost $83-84$ million barrels per day by the year 2030 and to 81 million barrels per day by the year 2035 [1]. However, the decline is significant in the last decade 2040-2050 where oil in transport is replaced by biofuels and electric vehicles. The oil share drops to around $15 \%$ in 2050 when following any of the examined main directions towards decarbonisation [3]. The United States, China and the European Union will play the main role in the oil demand dynamics, and the Middle East countries will critically affect the supply dynamics.

Table 1. Share of fuels in primary energy consumption in \% [1]

\begin{tabular}{|l|c|c|c|c|c|c|}
\hline & \multicolumn{2}{|c|}{ Reference scenario } & \multicolumn{2}{c|}{$\begin{array}{c}\text { Current policy } \\
\text { initiatives }\end{array}$} & \multicolumn{2}{c|}{$\begin{array}{c}\text { Decarbonisation } \\
\text { scenarios }\end{array}$} \\
\cline { 2 - 7 } & 2030 & 2050 & 2030 & 2050 & 2030 & 2050 \\
\hline Renewable & 18.4 & 19.9 & 19.3 & 23.3 & $21.9-25.6$ & $40.8-59.6$ \\
\hline Solids & 12.4 & 11.4 & 12.0 & 9.4 & $7.2-9.1$ & $2.1-10.2$ \\
\hline Oil & 37.1 & 32.8 & 34.1 & 32 & $33.4-34.4$ & $14.1-15.5$ \\
\hline Gas & 22.2 & 20.4 & 22.7 & 21.9 & $23.4-25.2$ & $18.6-25.9$ \\
\hline Nuclear & 14.3 & 16.7 & 12.1 & 13.5 & $8.4-13.2$ & $2.6-17.5$ \\
\hline
\end{tabular}

The largest increase is observed in solar energy. It is from $2 \%$ of global electricity production in 2019 to $22 \%$ in 2050 . It is expected that about $330 \mathrm{~kW}$ in each $1 \mathrm{MW}$ of this photovoltaic energy will be used by households and businesses, and will be $5 \%$ of global electricity in 2050 [9]. Wind energy will produce $26 \%$ of the world's electricity in 2050 , which is $5 \%$ more than it is now.

Renewable energy production accounts for approximately a quarter of the world's total energy production, which is a new record [2]. New record values were also recorded for plants operating on solar and wind energy, which showed an increase of $94 \mathrm{GW}$ for photovoltaic solar energy and $47 \mathrm{GW}$ for wind energy, including $4 \mathrm{GW}$ for wind energy in 
coastal waters [6]. Renewable energy production costs are declining. There is sufficient evidence that energy systems dominated by renewable energy sources can become a reality. Thus, the scale and pace of introducing renewable energy sources can be increased rather safely.

Biofuel is very rare in our country in comparison with the European and American markets. However, the market for solid biofuels is actively developing. Volumes of pellets and briquettes production are steadily increasing. In 2010, about 1 million wood and husk pellets were produced. The pellet market in our country is export-oriented. Specifically, up to $70-80 \%$ of production is exported to European countries. Russia is the third largest exporter in the world after Canada and the USA [7] with regards to European countries. At the same time, wood pellets are mainly bought by the Scandinavian countries, Central and Northern Europe, and husk pellets are bought by Great Britain and Poland.

As for the granules of chicken manure pellets, they are high-quality organic fertilizers. They contain all the elements (in a favorable amount and combination) necessary for plant nutrition. Also in recent years, they are increasingly practicing them as fuel for local use in gas boiler plants [4].

All pellets, regardless of what raw materials are used for their production, are divided into 2 large segments:

1. Consumer segment (first class granules). Such granules are supplied mainly to private consumers for use in domestic boilers and fireplaces. In such granules there are no impurities (bark, branches), binders.

2. Commercial (industrial) segment. Granules of lower quality are used mainly in medium and large thermal installations.

\section{Conclusion}

Despite the fact that Russia mainly focuses on the development of biofuels derived from wood waste, there remains a niche in the market, which is gradually being filled by enterprises that produce pellets from manure. As it was already mentioned, one of the promising areas is the production of biogas and bioenergy from poultry waste in special generating units. The introduction of these facilities will allow enterprises, in particular poultry farms, to achieve the following:

- Independence from rising rates and limits concerning electricity, heat and gas;

- Personal source of domestic gas, electricity and heat;

- Exemption of fertile arable land from lagoons for poultry waste storage;

- Freedom from environmental and waste management payments;

- An opportunity to increase the competitiveness of products and receive additional income.

Cost reduction through the use of personal sources obtained from production waste, such as slaughterhouse waste, fat and grease traps helps the company to be a leader in the competition. In addition, the strategy of the enterprise should be aimed at generating additional income through their processing [10] in biogas generation plants. Biogas generation plants not only utilize all organic waste from agriculture, food and wood processing industries but also produce biogas (Table 2). Biogas is produced under anaerobic conditions and is analogous to natural gas in composition.

Table 2. Waste suitable for producing biogas and its output.

\begin{tabular}{|c|c|c|}
\hline $\begin{array}{c}\text { Source raw material } \\
\text { (Humidity 86 \%) }\end{array}$ & Biogas output $\left(\mathrm{m}^{\mathbf{3} / \mathbf{t})}\right.$ & $\begin{array}{c}\text { Methane content in the } \\
\text { resulting biogas (\%) }\end{array}$ \\
\hline Slaughter waste & $250-300$ & $60-70$ \\
\hline
\end{tabular}


Table 2. Continued

\begin{tabular}{|c|c|c|}
\hline Poultry waste & $90-130$ & 60 \\
\hline Catch basin skimmings & $230-250$ & 60 \\
\hline
\end{tabular}

In addition, the cost of this installation is at least 3 times cheaper than foreign analogues. When using a semi-fixed cost option, an enterprise can benefit in the form of free heat, cheap electricity and gas, thereby reducing the cost of manufacturing basic products.

There is also a mini combined heat and power unit (CHPU) on a poultry waste made for the "Voronezh Turkey" agroholding. The CHPU is designed to burn up to 110 thousand tons of poultry waste per year (300 tons/day) with all the needs of a poultry processing complex (including a feed factory; a slaughter waste processing workshop for a feed additive; treatment facilities) in electricity (up to $5 \mathrm{MW}$ ), process steam $(2 \mathrm{t} / \mathrm{h}, 1.0 \mathrm{MPa}$, $190{ }^{\circ} \mathrm{C}$ ), hot water supply $(0.5 \mathrm{Gcal} / \mathrm{h}$ ) and heating (up to $2.5 \mathrm{Gcal} / \mathrm{h}$ ). An integral part of the CHPU is the workshop for processing ash into mineral fertilizer-soil conditioner with the capacity of up to 12 thousand tons per year [5]. As a result, the only waste is boiler flue gases. The level of harmful substances emissions does not exceed the level of burning fuel oil, and the most significant component is nitric oxide. However, the cost of this CHPU is quite higher than that of UPR. The installation of UPR allowed to reduce the cost of production by $25-30 \%$ in JSC "Sharkanskoye RTP" of the Udmurt Republic, LLC "Complex utilization systems" of the Orenburg region, peasant farm Rashin Perm Territory. Bio-energy plants will automatically solve the problem of poultry waste disposal and get heat and electricity for their own needs, which can bring additional profit to the enterprise and increase its competitive advantage. Such plants cost recovery is $1.5-2$ years.

\section{References}

1. Biofuels and food security, Report of the High Level Panel of Experts on Food Security and Nutrition of the Committee on World Food Security, Rome (2013)

2. J. B. Dahmus et al., IEEE Int. Symp. on Sustainable Syst. and Technol. (ISSST '09) (2009).

3. G. Eastwood, The Biofuels Market Outlook (2007)

4. Russia's energy strategy until 2020 (2003), http://www.energystrategy.ru

5. V. I. Fisinin, et al., Environmental protection technologies for the prevention of local environmental pollution by the waste of poultry farms (2018)

6. E. Hartman, A Promising Oil Alternative: Algae Energy (2008)

7. O. S. Sausheva, Internet j. Naukoved., 5, 59 (2016)

8. D. P. Smith, Principles and Applications, 549-566 (2014)

9. Weekly and monthly supply and demand of ethanol, https://ethanolrfa.org

10. L. A. Zazykina, L. M. Roiter, V. A. Gusev, IOP Conf. Ser. Earth and Environmental Sci., 315(7) (2019) 